\title{
Hall Marks in Construction Material Management: A Literature Review
}

\author{
${ }^{1}$ C.K.Georgekutty, ${ }^{2}$ Dr.Georgemathew
}

\begin{abstract}
Construction project implementation in India is still facing challenges. The main hurdles are failure to solve project specific problems. Generally projects taken up for implementation will never complete, in time or complete at a later stage leaving cost and time overrun. Researchers are trying to find out the reasons why projects could not complete in time. An exhaustive Literature review has been conducted. The research problem is identified and derived from the literature study.
\end{abstract}

\section{Introduction}

The success of a project depends on the ability to complete it in time, within the budget and the required quality. Planning is necessary to ensure proper utilization resources. This paper attempts to explore the present scenario with an objective to identify the project slippage areas which needs specific attention. The primary aim is to verify the system adopted in the construction implementation, technical competency, slippages, setbacks, technology adoption, methodology used, and lack of co-ordination in between agencies, development of positive relation-ships, failure to control the cost and time over run. The methodology adopted is an interaction study with the technical heads and promoters of the construction projects.

A questionnaire survey was conducted in selected projects spreading all over Kerala. The data obtained is analyzed by SPSS (Statistical Package for Social Sciences) and the results were examined in detail. The results obtained imply that, majority of the failures were due to the adoption of in-appropriate Engineering and Management technology, especially in Kerala. The authors from their past experience in this field suggest that further research is essential in each aspect separately for better results in project implementation. Most of the projects implemented are either not completed or complete at a later stage.

\section{Major Highlights}

Neeraj et.al.[2010] has expressed that approximately $42 \%$ of Indian government-funded construction projects are facing time overruns. In an earlier study conducted by one of the authors, A second-stage questionnaire survey based on these factors was used to identify the significant schedule performance factors. The analysis of the survey responses led to conclude that factors such as: a project manager's competence; monitoring and feedback by project participants; interaction between external project participants; and good coordination between project participants.

Heon [2011] has stated construction scheduling techniques often generate schedules that cause undesirable fluctuations in resource utilization levels and unintended peak resource demands that exceed availability limits. On the other hand, resource allocation or resource constrained scheduling models are designed to resolve resource conflicts by rescheduling project activities while minimizing the extension in project duration (Chen and Shahandashti 2009; Kim and Ellis 2008; Lee and Kim 1996; Leu and Yang 1999; Mingozzi et al. 1998; Zhang et al. 2006).

Fan [2011] states that scheduling delay is a common worldwide phenomenon in construction projects.Hegazy and Menesi (2008) found that scheduling delays occurred in 70\%, 40\% and 50\% of government contracted construction projects in the United Kingdom, India and United Arab Emirates (UAE) respectively.

Anderson [2005] has commented the research focused on engineering projects, typically complex and large in size since they are through likely to offer more comprehensive coverage and evidence of project management practices that can be transferred to smaller projects. Ibbs [2007] expressed that project delays caused damages to direct and indirect cost. Most of the previous research is based on construction projects in developed countries (Iyer and Jha, 2005). In recent years, the Indian construction industry has witnessed the arrival of impending projects related to infrastructure development, airport expansion, metro rail, and power sectors.

Love [2000] states that field overhead damages require proper estimation, even though it is less complicated than home, office overhead charges. Saka, and Mudi. [2007] observed that most of the contractors of Nigerian construction companies, collected materials locally, instead of collecting them from suppliers. 


\section{Pre-Project Planning}

Project planning is the most important aspect in project execution. Pre-planning of a project will give ideas about the cost of the project, start of the project, end of the project, duration of the project, and the extent of the project. Pre-planning of a project gives the requirement of various resources in each time. Planning the entire project form its inception to completion requires a detailed coverage and various types of plans.

Golparvar et.al. [2011] suggested that to facilitate progress monitoring, this paper proposes visualization of performance metrics that aims to represent progress deviations through superimposition of fourdimensional (4D) as-planned model over time-lapsed photographs in single and comprehensive visual imagery. Iyer [2006] states that Indian construction projects are facing time overrun. The reasons for this are being studied by researchers to suggest possible remedial measures. The important topics under research were in project management in the concept of project success Ashely et.al.[1987].

Martin [2004] explains that most of the research has been taken up in developed countries, and their applicability in developing countries such as India, is yet to be explored. Chan and Kumaraswamy [1994] state that the phenomenon in India is the same as that of other places. Anderson [1983] expressed that a questionnaire survey is the bridge between researchers, and respondents. The questionnaires are the vital elements which perform the actual interrogation. Heon et.al.[2011] reported that the objective of this module is to search for and identify a set of optimal schedules thatsimultaneously minimize project duration and maximize resource utilization efficiency forconstruction projects. Rey et.al.[2011] stated that several research investigations are available in the literature for overhaul planning subject to budget constraint. Because the decision problem is similar in other maintenance settings, the review extends beyond the water management arena. Bargeron [1995] proposes an integer programming formulation to plan depot maintenance of a fleet of military systems. His model minimizes the average age of the fleet, in which age is a measure of usage corresponds to the number of miles since the last overhaul. The hypothesis is that readiness decreases with age. Bargeron (1995) considers depot capacity constraints and a required minimum level of availability. In the field of facility management, Frangopol et al. (2004) review probabilistic models for lifecycle performance of deteriorating facilities.

Andy et.al.[2005] stated that sub-contracting plays a vital role in the construction industry as it is often used as a strategy to deal with long-term environmental uncertainties and to buffer the technical core of main contractors against short term contingencies. Sherif et.al. [1999] comments that the significance of pre-project planning. Most of the construction projects begin with a recognition of the need for a new facility.

Choi et.al. [2011] from their studies and research findings emerged from the analysis of projects are as follows.

$\square \mathrm{I} / \mathrm{D}$ projects held a definitive schedulesaving advantage over other contracting strategies.

A+B projects showed a severe problem with schedule delays.

As illustrated by capacityadded projects shows a higher degree of dispersion of ratios on A+B projects, suggesting that they did not start with well-defined project

Chine [2011] illustrates that the purpose of construction management is to successfully accomplish projects, which requires a continuous monitoring and control procedure. To dynamically predict project success, this research proposes an evolutionary project success prediction model (EPSPM). The model is developed based on a hybrid approach that fuses genetic algorithms. Shields et al.[2003] established a metric for measuring the success of the construction phase of projects. Chan et al. (2004a, 2005) developed a conceptual framework on critical success factors. Five major groups of independent variables: namely, project-related factors, project procedures, project management actions, human-related factors, and external environment, are identified as crucial to project success.

Choi,et.al. [2011] offering contractors a monetary incentive in exchange for shortening construction times provides state highway agencies with an innovative means to fulfill the public's desire that projects will be completed early. Tam and Harris [1996] developed a model to predict the performance of the main contractors in local construction projects from the client's perspective.

Hewn et.al. [2011] states that the objective of this module is to search for and identify a set of optimal schedules that simultaneously minimize project duration and maximize resource utilization efficiency for construction projects. The multi-objective genetic algorithm is implemented in the present model to generate optimal tradeoffs between optimizing these two objectives. Deb et al. [2001] in their studies the algorithm utilizes the concept of Pareto optimality to enable multi-objective optimization and the survival of the fittest criteria to evolve solutions over a number of specified generations until it reaches optimal/near optimal solutions.

Iyer [2003] conducted a series of studies and concluded that construction project slippages in India are mainly due to the following three sectors- Project planning, designing, implementation and material procurement and storage. Efforts have been made during the last sixty years, to improve technology in the construction industry. These efforts have resulted in the adoption of new technology.

Sturges [2000].expresses his views that several management techniques are available for use in implementing a project successfully. "Construction planners need to schedule and select appropriate resources, including crew sizes, materials, equipment and plant, to execute a construction project. These resources are 
essential for the successful completion of the project". Rey et.al. [2011] comments that several research investigations are available in the literature for overhaul planning subject to budget constraint. Bargeron (1995) proposes an integer programming formulation to plan depot maintenance of a fleet of military systems. His model minimizes the average age of the fleet, in which age is a measure of usage corresponds to the number of miles since the last overhaul. The hypothesis is that readiness decreases with age. Bargeron (1995) considers depot capacity constraints and a required minimum level of availability. In the field of facility management, Frangopol et al. (2004) review probabilistic models for lifecycle performance of deteriorating facilities.

Sherif [1999] et.al.comment that construction organizations have to overcome many problems in order to achieve high quality performance.

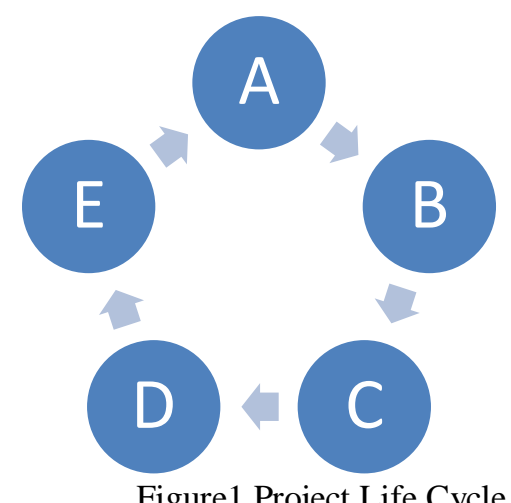

A. Feasibility Analysis

B. Project design

C. Pre-project planning

D. Project execution

E. Operation.

According to Gibson et.al. [1994] pre-project planning can be defined as the process of developing sufficient strategic information for owners to adjust risk, and decide to commit resources to maximize the chance for a successful project. Projects are planned either sequential or concurrent method. The system of sequential pattern is shown in Figure.2

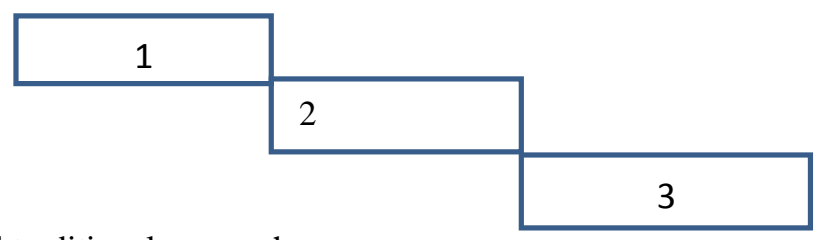

Figure.2 Sequential traditional approach

There are several advantages as well as disadvantages to this approach. They are briefly listed below.

1. Client's decision

2. Engineering Drawing

3. Construction

Each stage is completed prior to commencement of next stage. The sequential stage leaves some dis-advantages which are listed as follows.

a) The decision regarding the budget for building the facility is generally based on the assessment of the feasibility report without assessing the exact estimate.

b) Delays the project as the contract is finalized after the finalization of the design.

c) The subcontractor who is responsible for the quality and performance of the completion of the project.

d) The attitude to keep minimum quality and quantity by the subcontractor leads to conflict between the client and contractor.

Taek et.al. [2005] states that the fast-track approach to design and construction was developed in the early 1960s and became mainstream by the 1970s."Fast tracking" is generally defined as the compression of the design and/or construction schedule through overlapping of activities or reduction in activity durations (Fazio et al. 1998; Clough and Sears 1991; Williams 1995; Songer et al. 2000). Fast track approaches are not without problems. Fast tracking can often lead to schedule failures and project schedule slippage as the coordination of multiple contracts becomes more complex or when there is not a cooperative environment among the project parties. 
The fast-track approach to design and construction was developed in the early 1960s and became mainstream by the 1970s. "Fast tracking" is generally defined as the compression of the design and/or construction schedule through overlapping of activities or reduction in activity durations (Fazio et al. 1998; Clough and Sears 1991; Williams 1995; Songer et al. 2000). Fast track approaches are not without problems. Fast tracking can often lead to schedule failures and project schedule slippage as the coordination of multiple contracts becomes more complex or when there is not a cooperative environment among the project parties.

Due to the reasons sequential method is not suitable for a project to be completed in time. The concurrent method is shown below as Figure.3

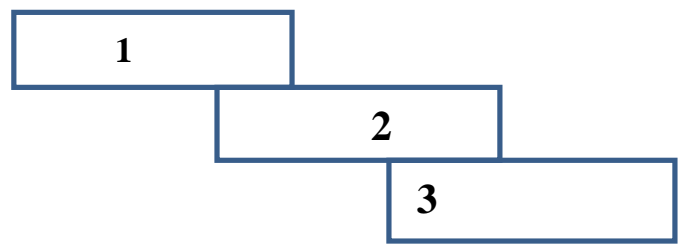

Figure 3 Fast track approach.

1. Owner's decision

2. Engineering drawing

3. Construction

4. Advantages

1. By studying the schedule of any project and the many alternative methods of execution, can choose for the best one.

2. It gives a clear idea about the various resources at every stage.

3.The starting of the project is known proper arrangements and requirements can be done.

4. Resource utilization is optimized.

5. Actual progress of the work is monitored

6. Interrelationship of various activities at each stage can be known.

7. Total duration to complete the project can be known. Usually bar chart and network analysis are used to represent scheduling.

Golparvar et.al. [2011] states therefore, to facilitate progress monitoring, this paper proposes visualization of performance metrics that aims to represent progress deviations through superimposition of fourdimensional (4D) as-planned model over time-lapsed photographs in single and comprehensive visual imagery. Ren [2008] explains that some of the researchers found that construction is delayed due to rapid growth of construction, tight construction schedule, involvement of International contractors, Unique architectural features, etc. based on Dubai Constructions. "Material procurement system and operational environments, the booming building and construction Industry, is facing many unique challenges which affect project progress". Ren [2006], also comments "Factors such as rapid growth in construction, tight construction schedule, unique architectural features, the involvement of international contractors and consultants, multinational work forces, unique culture and religion, readily available investment, and mixed contracts, and conditions generate particular impacts on construction project progress."

Researchers established the common causes of project delays after several studies identified in these research projects as in three sectors like Client, Consultant, and Contractor. The second important aspect is late approval of payment. Ko et.al. [2011] has the opinionthat purpose of construction management is to successfully accomplish projects, which requires a continuous monitoring and control procedure. To dynamically predict project success, this research proposes an evolutionary project success prediction model EPSPM. Success on a project means that certain expectations for a given participant are met, whether owner, planner, engineer, contractor, or operator Sanvido et al. [1992].

Kumaraswamy,[1996] expressed that, project success is based on not only effective project management. Project success is measured against the overall project objectives. Project success is also based on the primary objectives namely time, cost and quality. It depends on the effectiveness in implementation. Donyavi [2009], stated, that "The materials cost on a project can represent anything from $30 \%$ to $70 \%$ of the cost of the work. Donyavi, and Elangan [2009] stated that effective material management on construction site can reduce project duration and improve performance effectiveness.

\section{Resources in Construction}

The main objective of any construction project organization is to utilize the resources to the optimum level. The availability of certain resources may fluctuate due to various reasons. The intention is not to waste the resources. Hisham [2010] Material procurement and storage on construction sites need to be properly planned and executed to avoid the negative impacts of material shortage or excessive material inventory on-site. 
Deficiencies in the supply and flow of construction material were often cited as major causes of productivity degradation and financial losses (Thomas et al. 2005).

Efficient planning of materials procurement and storage on construction sites can lead to significant improvements in construction productivity and project profitability. Overlooking these critical interdependencies between material procurement and site-space availability can lead to serious project problems including material shortages, improper storage, poor and unsafe site layout, and productivity losses (Bell and Stukhart 1987; Thomas et al. 1989; Jang et al. 2007). Accordingly, there is a pressing research need to investigate and model the critical interdependencies between material procurement and material storage decisions. The objective of this paper is to present the development of a construction logistics planning (CLP) model that is capable of integrating and optimizing critical planning decisions of material procurement and material storage on construction sites.

Said et.al. [2011] explained that Material procurement and storage on construction sites need to be properly planned and executed to avoid the negative impacts of material shortage or excessive material inventory on-site. Guo, [2011] states that the effective implementation of LCM in construction projects relies strongly on a visual communication and collaboration information platform (Ameri and Dutta 2004; Garetti 2004) as information sharing is the key to implementing LCM (Schilli and Dai 2006). An effective information platform is needed to gather project information (Gross and Fleisch 2004) and furnish relevant information (from planning to decommissioning) to each participant Krause and (Kind 1998).

Orabi, et. al [2010] states that the main purpose of this model is to allocate limited reconstruction resources to competing recovery projects in order to generate a recovery schedule for the damaged civil infrastructure system. Bhargavalet.al.[2010] states that Worldwide, cost and time overruns on highway projects are critical issues that adversely affect project delivery and public relations, and disrupts highway programs. (Rowland 1981); Jacoby 2001; Tawiahet.al. [2008] states the term procurement system has been defined as "the framework within which construction is brought about, acquired or obtained" (McDermott 1999)

Anderson .et.al.[2005] comments the research focused on engineering based projects, typically complex and large in size since they are thought likely to offer more comprehensive coverage and evidence of project management practices that can be transferred to smaller projects.

Harper et.al. [2005] states that the comments the Construction Industry Institute (CII) investigated the traditional relationships between the owner, EPC contractor, and supplier to study an alternative method to procure major equipment items for capital projects

Bogus et.al.[2005] states that one way to reduce overall project delivery time _from design through construction is to reduce design delivery time through the overlapping of sequential activities. A key to overlapping activities is management of the information transfer between activities.

Cho et.al. [2010] expressed that since the early 1990s, the use of the design-build approach in the public building sector has flourished. Documented design-build success and a number of high-profile projects in both the public and private sectors have been encouraging public owners to utilize this innovative process

Emre et.al.[2011] Management of Cost and Schedule in the Construction Industry Cost and schedule are two of the most important project components in the construction industry. Flyvbjerg et al. (2002) found that project costs were underestimated in $90 \%$ of the 258 infrastructure projects completed in the past 70 years around the world.

Hastak (1994) presented a prototype decision support system called the cost management planning support system (COMPASS) for project cost control strategy and planning. Jergeas, [2010] expressed his viewsmore and more megaprojects are built despite the poor performance record of many projects. According to Flyvbjerg (Flyvbjerg et al. 2003), the main causes of the megaproject overrun are the inadequate deliberation about risk and lack of accountability in the project decision-making process.

Sung .et.al.[2005] although many innovative management processes are available in the industry, there has been remarkably little research on the subject of selection of these management processes.

Castro et.al.[2009] construction management decisions are made based on schedules that are developed during the early planning stage of projects, yet many possible scenarios should be considered during construction. Decisions could be made that rely solely on the expertise of DMs that use commercial software such as Primavera Project Planner (P3), Primavera Project Management (P5) or Microsoft Project but sometimes the assumptions that are made during the planning stage of a project change during construction.

Fan [2011] states that delay claims are a common occurrence in construction projects. Many techniques have been developed to assess these delays. The time impact technique is the preferred approach for resolving complex disputes that are related to delays and delay compensation. However, this approach is time consuming and costly to operate. Scheduling delay is a common worldwide phenomenon in construction projects. Hegazy and Menesi (2008) found that scheduling delays occurred in 70\%, 40\% and 50\% of government contracted construction projects in the United Kingdom, India and United Arab Emirates (UAE) respectively. Many techniques have been developed and employed to address scheduling delay claims, including the global impact technique, the net impact technique, the as-planned versus as-built technique, the impacted as-planned analysis, 
the but-for technique, the time impact technique, the snapshot technique, and window analyses. Of these, the time impact technique is the preferred approach used to resolve complex disputes related to delays and delay compensation (SCL 2002).

\section{IV.1 Time Impact Analysis}

The Time Impact Analysis (TIA) technique, also known as end of every delay analysis, chronological and cumulative approach or the modified as-built technique (Ndekugri et al. 2008), examines the delay effects that occur during the course of a project's progress. The delay to the project is defined as the difference between the projected completion dates of the two stages, while the total project delay duration is defined as the sum of all delays over the life of the project (Kumaraswamya and Yogeswaranb 2003; Arditi and Pattanakitchamroon 2008).

Wamuziri. [2009] suggested a method- reverse auction in procurement of construction materials. The main advantage of this method is that we can develop a high competition in bidding the price of construction material and choose the lowest bidder irrespective of the quality of service or material they supply. Ofori [2000] explains that the construction industry is having poor co-ordination. This was borne out by our interviews. Poor planning leads to inefficiency, low productivity, excessive waste, and health and safety problems. Straight forward and affordable technologies are available but not fully implemented in construction. Further this will lead project loss and time.

Faniran et.al. [1994] reported that lack of planning is one of the major problems for construction. Seetharaman [2003] states that Construction Materials and components contribute around 50-60\% of the total value of construction. Seetharaman also comments that procurement of materials directly affects operations and profits. Materials of poor standards and ineffective quality control will cause delay in the implementation of the project and the resources may also get wasted, thus increasing the overall cost of the project.

Asnaashari et.al.[2009] reveals that delay is often the result of an unpredicted event that does not necessary, indicate that the management system is ineffective. Most of the construction projects that there are common causes of delay that frequently happen in their material procurement. Identifying these may help practitioners to anticipate potential delays and plan to minimize their effects. Jackson [2002] explained that the construction industry has a reputation for delivering projects over budget. This research identifies why building construction projects sometimes exceed the initial budget estimate. The study concluded that in design changes in a project is the key reason for cost overrun.

Mezher and Tawil [1998] has explained that the construction delays in Lebanese construction projects are due to the delay in preparation and approval of drawings, slowness of the owner's decision making process, delay in obtaining permission from different Government authorities, non-availability of materials on time and unskilled manpower are the major causes of delay. The present study explains the causes of construction projects in in Iran. The causes of delays are associated with project management, logistics, technology and the environment.

Construction project slippages in India are mainly due to the following three sectors- Project planning, Project designing, and Implementation These efforts are bringing light for the adoption of new technology. A country's economy is depending on the growth of construction industry, since this is the second largest industry in India. [Iyer. 2003]. Joy [2010] highlights that inventory control is exercised on stock carrying. Resource allocation substantially influences project time. In-practical allocation may account project delay. Material management is not just a concern during the monitoring stage.

Guo,[2010] Commented that the effective implementation of LCM in construction projects relies strongly on a visual communication and collaboration information platform

Rasheed [1998] has reported that there are constraints in procurement Malaysian Construction Industry. The size of the Malaysian construction industry is small. There are several issues prevailing. The issues including (1) The relatively poor performance of construction in terms of failure to implement planned development projects Yaacob [1996], of failure to meet target delivery dates Abdullaha 1995 and Yaacob [1996] and the poor health and safety records on construction sites Abdullah [1995] and Yaacob [1995] and (2) continues and upward increases in construction prices (Master Builders Association of Malasia, 1989/90 and 1996: Ministry of Finance 1988-95). Donyavi.and Flanagan. [2009] has stated that the materials on a project can represent anything from 30\% to $70 \%$ of the cost of the work. Donyavi suggests Material management is the system for planning and controlling to ensure that the right quality and quantity of materials and equipment are specified in a timely manner.

Wamuziri. [2010] stated that in Scotland, most of the infrastructure projects signed has been delivered through PFI/PPP, procurement model. This has found largely success in delivering major infrastructure projects both in the UK and internationally. The basic objective of the resource management is to supply and support the field operations. As stated by Bhargava1[2010], cost and time overruns on highway projects are critical issues that adversely affect project delivery and public relations, and disrupts highway programs. 
According to Chan and Kumaraswamy [1997]; Chang [2002]; Flyvbjerg et al. [2004]; and Bordat et al. [2004], most approaches used to analyze cost overrun and time overrun events proceed by considering that cost overruns and time overruns as separate events and thus are modeled separately. The time overruns and cost overruns simply ignore the fact that many explanatory variables in such models are not truly exogenous, independent variables. Dulaimi, and Kumaraswamy, [2000] finds that in a developing country like India the method of procurement and carrying are entirely different. In most of the projects, the project reports are not finalized before implementing the project. Hence resources are not planned and well defined. Procurements are always approximation and based on the project estimate which is tentative Ibbs [2007] comments that resource allocation substantially influences project time performance. Unfortunately current schedule analysis often does not consider a project's resource allocation.

\section{Construction Materials Management}

An extensive study of the literature survey revealed that projects are implementing without a specific method in construction material procurement and storage. It is usually done by approximation based on the project estimate. As a result the procurement cost andstorage cost is high, which leads to huge overheads in projects. The literature study leads to a conclusion that construction projects will suffer slippages at the beginning to every stages of its implementation and finally project loss is the net result. The major area of loss is identified in procurement and carrying of construction materials. A new approach has suggested through this paper. This can be adopted as a general method to other projects.

\section{Materials Resource Management}

Completion of a construction project at maximum efficiency of time and cost requires proper planning and constant follow up. It also requires the availability of resources like man power, equipment, and materials, and the proper resource allocation of resources and their availability in time. The non-availability of resources in time may cause project delay. The project manager is responsible to identify and schedule future job needs so that the most efficient use is made out of the resources available. The project manager must determine long range resources for general planning and short term resources for detailed planning. [Tawiah] defined the term procurement system as "the framework within which construction is brought about, acquired or obtained" Although there is general agreement on the critical role of innovation in the procurement process, the strategy for implementing and achieving beneficial innovation by choosing the most appropriate procurement mode and accompanying terms has been the subject of much discussion among practitioners, policy makers, researchers, and other project stakeholders.

Gamage et.al. (2009) insisted the need of identifying of a suitable controlled purchase system for the management of design and construction process to control the material wastage. They also suggests that quality, cost and time are often adopted as primary performance measures on construction projects. Although there have been many attempts to improve performance, limited success has been achieved (Egan 1998). One reason for this is the difficulty in focusing on just one performance measure and the need to take in to account other inter related factors. Modern construction project procurement faces ever-increasing problems in managing and dynamically responding to changes in the environment and the needs of their clients, particularly in the construction material procurement area (Udeaja. 200).

Monitoring and control are attempts to spot problems while the project has in the execution stage. The dynamic performance of a project manager is the key in making a project in to a success. The role of a project manager has got vital contribution to the smooth progress of a project. Co-ordination and team building has an integral part in implementation of construction projects (Sheeran, 1976). Sheeran (1976) considers co-ordination as one the principal functions of management. "A team is a small number of people with complementary skills who are committed to a common purpose, set of performance goals, and approach for which they hold themselves mutually accountable". In an effort to complement team understanding with in the environment they perform it may be reasonable "to focus attention on how aspects of organizational context influence the different forms of team working adopted". (Buchanan,2000).

Pre-project planning can be defined as "the process of developing sufficient strategic information for owners to address risk and decide to commit resources to maximize the chance for a successful project. Gibson and Hamilton (1994) demonstrated that achieving project objectives in terms of time, cost and quality is closely related to the efforts spent during the pre-project planning phase. Similar view is expressed by Sullivan et.al. (1997) who emphasized that more time and effort devoted at this phase will increase the chance of a project being successful

Success of a project depends on the ability to complete it on time within the budget and as per the required quality. Efficiency of a construction firm is the timely completion of its projects. Ibbs (2007) expressed that project delays caused damages to the direct and indirect cost. Delay of a project during its progress would suffer material loss, machinery idling including tools and plants and equipment Love (2000). Field overhead damages required proper estimation, even if it was less complicated than home offices overhead charges. Saka, 
andMudi (2007) found that the Nigerian construction companies, and most of the contractors collected materials locally instead of collecting from suppliers to maintain long inventory. Modern methods like information and communication technology were not applied. The important topics under research were in project management in the concept of project success Ashely et.al.(1987)

The Indian construction Industry has gained far more importance in recent times because of the opening up of Indian Markets. The time overrun is the main cause of cost over run and it affects both clients and contractors. Chang [2010] showed the fast-track approach to design and construction was developed in the early 1960s and became mainstream by the 1970s. "Fast tracking" is generally defined as the compression of the design and/or construction schedule through overlapping of activities. As fast track and design-build delivery evolved in the public sector, partnering practices to enhance the relationship between the contractor and the owner in the construction industry concurrently were developed_Pocock et al. 1996; Gransberg et al. (1999). The Construction Industry Institute defines partnering as "a commitment between two or more organizations for the purpose of achieving specific business objectives by maximizing the effectiveness of each participant's resources.

Chan and Kumaraswamy (1994) stated that in India the phenomenon was the same. Usually projects taken up in India would be completed at a later stage, or would remain incomplete, and in both cases the end result would be the same. The project would end up with time over run with some reasons. Anderson (1983) expressed that a questionnaire survey was the bridge between researchers, and respondents. The questionnaires were the vital elements which performed the actual interrogation.

Iyer (2003) states that construction project slippages in India are mainly due to the following three sectors- Project planning and designing, implementation and material procurement and storage. For more than sixty years, efforts were being made to improve the technology in the construction industry. These efforts are the best fits for the adoption of new technology. A country's economy depends on the growth of construction industry, since this is the second largest industry in India.

Sturges, (2000).showed that several management techniques are available for implementing a project successfully. "Construction planners need to schedule and select appropriate resources, including crew sizes, materials, equipment and plant, to execute a construction project. These resources are essential for the successful completion of the project" Ren (2008) explained that some of the researchers found that construction was delayed due to rapid growth of construction, tight construction schedule, involvement of international contractors, unique architectural features, etc. on the basis of Dubai construction. In Dubai the economic growth is high The demand of large scale and high quality projects are high. At present there is no accepted system in construction implementation and procurement and carrying system of construction materials. "Material Procurement system and operational environments, the booming building and construction Industry, is facing many unique challenges which affect project progress". Factors such as rapid growth in construction, tight construction schedule, unique architectural features, the involvement of international contractors and consultants, multinational work forces, unique culture and religion, readily available investment, and mixed contracts, and conditions generate particular impacts on construction project progress Ren, Z (2008)

Tools used for the previous researchers - SPSS -17, EFA, CFA, Cronbach's alpha, SEM, Reliability are checked to find the consistency of the questionnaire survey.

\section{Tools and Techniques}

This session deals with the major tools and techniques used for the research. Scale refinement and validation- validity is the most critical evaluation and indicates the degree, what it supposed to measure. The major forms of validity are content validity, construct validity, and face validity

The EFA, CFA and Cronbach.s alpha scale reliability coefficient. Alpha to overcome the limitations of EFA analysis. CFA is used in stages of scale refinement and validity. Reliability depends on the degree of dependability, Consistency, and stability, of a scale. Internal consistency is estimated by using Cronbach's Alpha. An alpha value is above 0.7 is considered to be strong, and above 0.6 is considered to be significant. In the EFA test, the Kaiser Meyer - Oklin value were 0.656, 0.626, and 0.688 respectively in Technology, Material, and Success. This is supporting the factorability of co-relation matrix.

Confirmatory factor analysis- Structural equation modeling (SEM) was performed to test the fit between the research model and the data obtained. All values in this test are in the acceptable limit.

Content validity-.Systematic examination of the test to determine whether to cover a representative sample of behavior domain to be measured.

Face validity- to estimate whether the test appears to measure certain criterion. Face validity is very close to content validity.

Convergent validity- is one of the approaches to construct indication of strong convergent validity.Unidiamensionality analysis is a necessary condition for reliability analysis and construct validation. The comparative fit index value 0.9 or more indicates strong Uni-diamensionality. 
One sigma limit- The mean score greater than the upper limit is classified as excellent.

\section{Structural equation modeling for finding the dominating factor}

The main aim of the study is to investigate the extent to which the Technology Acceptance and material management explains the success of the of the Multi-Story Construction project The research hypothesis is:

\section{H1: the success of the Multi-Story Construction project significantly influenced by the adoption of project planning and material management.}

In this chapter we use the factor analysis method both exploratory factor analysis (EFA) and confirmatory factor analysis (CFA) approach, to identify he dominating factor of the success of the Multi-Story Construction project. The 15 -item scale was designed to measure problems and success of Multi-Story Construction project. The subjects were asked to respond using a five-point scale (strongly agree, agree, neutral, disagree, and strongly disagree). The score 1 represented the option "strongly disagree" while score 5 on the scale represented the category "strongly agree.

\section{Scale refinement and validation}

Validity is the most critical evaluation and indicates the degree to which instrument measures, what it is supposed to measure. Validity can also be considered as utility, in other words validity the extent to which, differences found with a measuring instrument reflects the true differences among these being tested. Empirically validated scales can be used directly in the other studies in the field for different programs. A scale for a construct is useful for application by different researchers in different studies if and only if , it is statistically reliable and valid. The major forms of validity are content validity, construct validity and face validity

\section{Different approaches to scale refinement and validation Exploratory factor analysis (EFA)}

The major approaches used by the researchers for scale validation and refinement are EFA and CFA. EFA is a conventional approach to scale refinement consists of following steps a) identifying the items relevant to the particular domain from literature b) Designing a survey instrument to measure these items c) Conducting a field survey d) performing EFA (often with varimax rotation) on the item responses to identify the major factors according to the item factor loading and e) Refining the scales using cronbach's scale reliability coefficient alpha. The major disadvantage of pure exploratory factor analysis lies in the difficulty involved in interpreting the factors. The EFA is done using SPSS-17.

To overcome the inherent limitations of EFA, the scale refinement and validation using the alternative approach has been pursued. This approach uses CFA in various stages of scale refinement and validation. CFA is similar to EFA except that the hypothesis that form constraints are embedded in the analysis .Research in social sciences and marketing disciplines has increasingly preferred this approach due to its conceptual strength.

\section{Confirmatory factor analysis (CFA)}

CFA is a type of structural equation modeling (SEM), which deals specifically with measurement models, that is relationship between observed measures or indicators (eg. Test items, test scores etc) and latent variables or factors. A fundamental feature of CFA is its hypothesis -driven nature. in CFA, the researcher specifies the number of factors and the pattern of indicator of indicator factor loading in advance, thus the researcher must have a firm a prior sense, based on past evidence and theory of the factors that exist in the data. CFA is used for four major purposes 1) psychometric evaluation of measures (questionnaires) 2) construct validation 3) testing method effects and 4) testing measurement in variance (across groups or population). In social research works, researchers need to have measures with good reliability and validity that are appropriate for use across diverse populations. Development of psychometrically sound measures is an expensive and time consuming process, and CFA be one step in the development of process, because researchers often do not have the time or resources to develop a new measure, they may need to use existing measures. in addition to savings in time and costs, using existing measures also helps to make research findings comparable across studies when the same measure is used in more than one study. However, when using existing measure, it is important to examine whether the measure is appropriate for the population included in the current study. in these circumstances, CFA can be used to examine whether the original structure of the measure works well in the new population

\section{Reliability}

An assessment of the statistical reliability is necessary before any further validation analysis. Reliability refers to degree of dependability, consistency or stability of a scale. Unreliable scale will lack consistency of 
measuring the same item to the extent. There are four good methods of measuring reliability. Test-retest technique, multiple forms, inter-rater, Split half reliability, now a days, particularly for field survey internal consistency is estimated by using Cronbach's alpha. An alpha value of 0.70 or above is considered to be criterion for demonstrating strong internal consistency, alpha value of 0.60 or above is considered to be significant.

The statistical analysis comprised two stages. The first stage examined the descriptive statistics of the measurement items and assessed the reliability and validity of the measure used in this study. The second stage tested the proposed research model and this involved assessing the contributions and significance of the manifest variables path coefficients.

\section{Research Gaps Identified}

A major observation identified is inthe unit rate adopted in preparing the project estimate. It is not even based on the present day-to-day rate prevailing in the open market at the time of preparing the project estimate. The second major observation is, in every project there is an un-certainty existing in the total project cost when it is completed, or to complete the project. Third observation is regarding the total life of the project.

\section{Conclusion}

An extensive study of literature has been carried out in the area of construction project management and construction material procurement, storage and consumption to the project. From the literature review it is understood that this area require further research to find some feasible solutions to control the total project cost. This work is an attempt to find a method to control the procurement and storage cost in construction projects.

The field study is conducted in a very precise manner and confined area. A questionnaire survey is conducted in step by step and strictly observing on the principles adopted for a successful questionnaire survey. The response of the respondents received is analyzed by using the appropriate statistical tool. The results obtained were discussed in detail and the analysis observations are arrived. The study, leads to the fact that very few project are well planned before implementation and projects are always affected time overrun due to several reasons. There is no proper system for procurement of construction materials. Materials contribute more than $50 \%$ of the total project cost. So material management and control is a serious issue, and this study is an attempt to find a new method to control the material procurement and carrying cost.

An extensive study of literature has been carried out in the area of construction project planning and construction material procurement, carrying, storage and consumption to the project. This led to the gist of observation and gap identification in certain research areas. From the literature study, field knowledge, and the ongoing construction approach, and observations it is understood that certain areas require close attention as a precaution from project slippage. The research problem has derived from the observations. This give light to the fact that pre-planning and material procurement are equally important in the total project cost. As an after effect of the project delay cost and time overrun will be the end result of every project. This research work is an attempt to find a method to control the procurement and carrying cost in construction projects. Based on the motivation for the survey this research has been carried out which is elaborated in the subsequent chapters : At the outsets based on the attempts of the previous researches, an appropriate methodology has been designed and subsequently by the most suitable research instrument have been identified and the research is administered with implications for future researches and predations. The research problem is identified and defined.

\section{References}

[1] Abeysekera, V, McLean C, Akintoye, A (2001) "Project success and relationships from a stakeholderperspectivea pilot study". Association of Researchers in Construction Management Vol.1 PP.485-494.

[2] Abdullah, A. R. [1995] "Implication of the C I D B Act1994 on the Malaysian Construction Industry:" Unpublished paper, Construction Industry Development Board Malaysia.

[3] Akintoye, A (Ed). [2000] "Choosing concessionaires in BOT-type projects" Association of Researchers in Construction Management, Vol. 1, 395-404.

[4] Anderson D, Merna A. [2005] "Project Management is a Capital Investment Process" ". Journal of Management in Engineering. Vol. 21. Issue 4. October DOI: 10.1061/(ASCE)0742-597X(2005)21:4(173)

[5] Arbuckle, J. L. [2006]. AMOS (version 6.0) [Computer software], Chicago: SmallWaters.

[6] AbhishekBhargava, Panagiotis Ch. Anastsssasopoulos, Samuel Labi, Kumares C Sinha, and Fred L Mannering [2010] " Three Stage Least-Squares Analysis of Time and Cost Overruns in Construction Contracts.” Vol.136,No.11,PP.1207-1218.

[7] Bhargava1Panagiotis Ch. Anastasopoulos, Samuel Labi,Kumares C. Sinha, Hong and Fred L. Mannering,[2010] “Three-Stage Least-Squares Analysis of Time and Cost Overruns in Construction Contracts" Journal of Construction Engineering and Management, Vol.136 (11) PP 1207-1218.

[8] Baker, A C and Boyd, K J [1983] Fast- tracking for Nuclear power plant construction.

[9] Catell,R.B.[1966].Thescreetestforthenumberoffactors.Multivariate behavioral research, 1, 245-276.

[10] Choi.K, Young HoonKwak, Jae-Ho Pyeon, and Kiyoung Son[2011] "Schedule Effectiveness of Alternative Contracting Strategies for Transportation Infrastructure Improvement Projects" Journal of Construction Engineering and Management. Vol. 138, No. 3, PP 323-350.

[11] Choy, C V and Suk, CY[2005] "Critical Factors in The Successful Implementation of Knowledge Management”, June 2005.

[12] Cho K, HyunC, and Hong [2010] "Partnering Process Model for Public-Sector Fast-Track Design-Build Projects in Korea" Journal of Management in Engineering, Vol. 26, No. 1, PP. 19-29 
[13] Chien-Ho Ko and Min-Yuan Cheng [2007]“Dynamic Prediction of Project Success using Artificial Intelligence" Journal of Construction Engineering and Management Vol.133, No.4,PP.316-324 Dey, P K [2000] "Managing project in Fast-track - A case of Public Sector Organization in India". International journal of public sector management, Vol. 13(7) PP. 588-609.

[14] Dulaimi M F and Kumaraswami M M (2000) "Procuring for Innovation: "The integrating Role of Innovation in Construction Procurement" Association of Researchers in Construction Management. 16th Annual Conference, Vol. 1 PP. 303-312.

[15] David K. Anderson and Merna.A (2005) "Project Management is a Capital Investment Process" Journal of Management in Engineering, Vol. 21, No. 4, October 1, 2005. pp. 173-179

[16] Donyavi, S. and Flanagan, R. (2009) "The impact of effective material management on construction site performance for small and medium sized construction enterprises" 25th Annual ARCOM Conference, Albert Hall, Nottingham, pp. 11-20.

[17] Gamage, I.S.W., Osmani, M. and Glass, J,[2000] "An investigation in to the impact of procurement systems on waste generation: the contractors' perspective". 25th Annual ARCOM Conference 7-9 September 2009, Nottingham, UK, Association of Researchers in Construction Management,1031-1040.

[18] Jackson, S [2002] Project cost overruns and risk management, 18th annual ARCOM Conference, 2-4 September 2002, University of Northumbria. Association of Researchers in Construction Management, Vol. I, PP. 99-108.

[19] Kumar NeerajJha and CT Chockalingam [2011] "Prediction of schedule performance of Indian construction projects using an artificial neural network"- Construction Management \& Economics, 2011, vol. 29, issue 9, PP. 901-911

[20] Mani Golparvar-Fard, Feniosky Peña-Mora, Carlos A. Arboleda, and Sang Hyun Lee (2009); "Visualization of Construction Progress Monitoring with 4D Simulation Model Overlaid on Time-Lapsed Photographs" ASCE Journal of Computing In Civil Engineering Vol. 23, No. 6, pp. 391-404,

[21] Ibbs W (2007) "for Capital Projects"- Journal of Construction Engineering and Management, Vol. 131, No. 2, pp. 1096-1104

[22] Tennant, S and Lang ford, D (2005) "Construction Management Teams \& Project performance" - a diagnostic toolkit. 21st Annual ARCOM Conference, Association of Researchers in Construction Management, Vol.2,PP. 939-948.

[23] Wamuziri, S [2010] "Alternative models for procurement of major infrastructure projects in Scotland". 26th Annual ARCOM Conference 6-8 September 2010,Leeds UK, Association of Researchers in Construction Management Vol.2 PP.1009-1018.

[24] Paul A. Tawiah, and Alan D Russell [2008] "Assessing Infrastructure Project Innovation Potential as a Function of Procurement Mode" Journal of Management in Engineering Vol.24,No.3,PP173-186

[25] http://dx.doi.org/10.1061/(ASCE)0733-9364(1986)112:3(346) accessed on 17-11-2009

[26] Rasheed, K B A and Morledge, R [1998] "Construction Procurement Processes in Malasia: Constrints, and strategies". 14th Annual ARCOM Conference, Association of Researchers in Construction Management, Vol,2, PP. 506-16

[27] Scherif, M A and Price, A D F [1999] "A framework for pre-project Planning." 15th Annual ARCOM Conference, Association of Researchers in Construction Management, Vol 2, PP. 435-44.

[28] Iyer, K.C.andJha, K N [2003] "Analysis of Critical Coordination activities of Indian Construction Projects". 19th Annual ARCOM Conference, Association of Researchers in Construction Management, Vol. 2, PP. 563-72

[29] Iyyer K.C. and Jha K.N. [2006] "Factors affecting cost performance : Evidances from Indian Construction Projects", ASCE Journal of Construction Engineering and Management Vol.132,(.8) PP.-871-881

[30] IyyerK.C.andJha K.N.[2005] Factors affecting cost performance: Evidances from Indian Construction Projects, International journal of project management, UK,23 (4) PP 283-295

[31] Ibbs, W. and L.D. Nguyen, [2007] "Schedule Analysis Under the Effect of Resource Allocation," Journal of Construction Engineering and Management, ASCE, February 2007, Vol. 133, No. 2, pp. 131-138.

[32] Ren, Z, Atout,M and Jones, J [2008] "Root causes of construction project delays in Dubai". 24th Annual ARCOM Conference, Association of Researchers in Construction Management, PP. 749-757.

[33] Joy Dr. [2010] "Total Project Management”, Mac Milan Publishers India Ltd, Chapter Procurement cost control and Inventory cost control pp. 397-405.

[34] Rey et.al. [2011] "Integrated Model for Optimizing Strategic Overhaul Planning of Distributed Pump Station". Journal of Construction Engineering and Management. doi:10.1061/(ASCE)CO.1943-7862.000036

[35] Ho Ko et.al. N. Srinivas, N. Srinivas [2011] Dynamic Prediction of Project Success Using Artificial Intelligence Multi- objective Optimization Using Non dominated Sorting in Genetic Algorithms (C) 1994 by the Massachusetts Institute of Technology Vol. 2, No. 3, Pages 221-248

[36] Heon, E I Rayes K [2011] "Multi-objective Optimization of Resource Leveling and Allocation during Construction Scheduling" Construction Engineering and Management Vol.137 (12) PP 1080-1088. 